\title{
Investigations into, and development of, a lyophilized and formulated recombinant human factor IX produced from CHO cells
}

\author{
Aline G. Almeida - Rodrigo C. V. Pinto - C. Mark Smales $(1) \cdot$ Leda R. Castilho
}

Received: 17 April 2017/Accepted: 5 May 2017

(C) Springer Science+Business Media Dordrecht 2017

\begin{abstract}
Objectives To develop a recombinant human factor IX (rFIX) formulation equivalent to commercially available products in terms of cake appearance, residual moisture, proportion of soluble aggregates and activity maintenance for 3 months at $4-8{ }^{\circ} \mathrm{C}$.

Results $\mathrm{NaCl}$ and low bulking agent/cryoprotectant mass ratio had a negative impact on cake quality upon lyophilisation for a wide range of formulations tested. Particular devised formulations maintained rFIX activity after lyophilization with a similar
\end{abstract}

Electronic supplementary material The online version of this article (doi:10.1007/s10529-017-2353-y) contains supplementary material, which is available to authorized users.

A. G. Almeida - L. R. Castilho

Cell Culture Engineering Laboratory, COPPE, PEQ,

Federal University of Rio de Janeiro (UFRJ),

Cx. Postal 68502, Rio de Janeiro, RJ 21941-972, Brazil

A. G. Almeida - L. R. Castilho

IQ, Biochemistry Program, Federal University of Rio de Janeiro (UFRJ), Av. Athos da Silveira Ramos 149,

Rio de Janeiro, RJ 21941-909, Brazil

R. C. V. Pinto

FIOCRUZ, Biomanguinhos, Av. Brasil 4365, Pav. Rocha

Lima, Rio De Janeiro, RJ 21040-900, Brazil

C. M. Smales $(\square)$

Industrial Biotechnology Centre and School of

Biosciences, University of Kent at Canterbury,

Canterbury CT2 7NJ, UK

e-mail: c.m.smales@kent.ac.uk performance when compared with the rFIX formulated using the excipients reported for a commercially available FIX formulation (Benefix). rFIX remained active after 3 months when stored at $4{ }^{\circ} \mathrm{C}$, though this was not the case with samples stored at $40{ }^{\circ} \mathrm{C}$. Interestingly, particular formulations had an increase in residual moisture after 3 months storage, but not above a 3\% threshold. All four formulations tested were equivalent to the Benefix formulation in terms of particle size distribution and cake appearance.

Conclusions Three specific formulations, consisting of surfactant polysorbate-80, sucrose or trehalose as cryoprotectant, mannitol or glycine as bulking agent, L-histidine as buffering agent, and $\mathrm{NaCl}$ added in the reconstitution liquid at $0.234 \%(\mathrm{w} / \mathrm{v})$ were suitable for use with a $\mathrm{CHO}$ cell-derived recombinant FIX.

Keywords Excipients - Formulation - Freezedrying - Lyophilization - Recombinant factor IX . Stability study

\section{Introduction}

Factor IX (FIX) is a vitamin K-dependent serine protease that is part of the blood coagulation cascade and its congenital deficiency causes a bleeding disorder, hemophilia B (Lim et al. 2010). Treatment of this disease has traditionally involved intra-venous infusion of recombinant or human plasma-derived protein concentrates of Factor IX. It is more desirable to use 
recombinant material where control over its manufacture and source is possible, with Factor IX usually being expressed in recombinant mammalian cell lines (Amaral et al. 2016) although its expression in insect cells has also been reported (Vatandoost and Bos 2016). One obstacle in developing efficient therapeutic products containing Factor IX is that the protein is sensitive to both chemical and physical degradation. As such, specific formulations and preparations must be developed that allow the delivery of a stable and active Factor IX preparation.

Aqueous preparations of FIX often have insufficient shelf-life for delivery and use in the clinic, being unstable (Smales et al. 2002) and tending to lose their biological activity, even if stored at low temperature (Webb et al. 1997). Thus, freeze-drying to generate lyophilized preparations represents a reference process for the manufacturing of high-quality drug products with appropriate stability for long-term storage (Lim et al. 2016). The final drug formulation before the freeze drying process needs to provide protein stability through all the stresses imposed during the freeze drying process, long-term storage and reconstitution (Jameel and Pikal 2010). Currently, formulation development is reliant on trial and error knowledge-based approaches for each target molecule. Therefore, the relationship between protein instability, formulation excipients and their concentrations needs to be carefully evaluated for each therapeutic protein. The purpose of this work is to report on the relationship between excipient composition and Factor IX stability, seeking an alternative formulation which is able to maintain the commercially important Factor IX protein stability after lyophilization with appropriate cake appearance, acceptable levels of residual moisture and retention of biological activity for at least 3 months.

\section{Materials and methods}

Production of purified recombinant factor IX

The recombinant Factor IX (rFIX) used in this study was produced according to a confidential upstream and downstream process developed at the Cell Culture Engineering Laboratory of UFRJ (Brazil). In summary, rFIX was produced by $\mathrm{CHO}$ (Chinese hamster ovary) cells engineered to expression human Factor
IX. Cells were cultivated in batch or fed-batch mode in stirred-tank bioreactors, and rFIX from the cell culture harvest material was purified using a two-step process based on membrane adsorbers, which was adapted from Ribeiro et al. (2013). Factor IX protein concentration was assessed by ELISA.

Preparation, lyophilization and reconstitution of samples

Throughout this work, samples of each tested formulation (Table 1) were prepared by buffer exchange using Amicon Ultra $10 \mathrm{kDa}$ cut-off membrane (Millipore). Lyophilization of $1 \mathrm{ml}$ samples was carried out using a Virtis SP Scientific Advantage Plus lyophilizer instrument and the software Synwiz-Plus. The volume used for reconstitution of lyophilized samples was the same as starting volume of samples $(1 \mathrm{ml})$.

\section{Differential scanning calorimetry (DSC)}

To determine the annealing temperature to be used in the lyophilization process, samples formulated according to the excipients of two commercial products (Benefix and Rixubis) were analyzed on a DSC Q 200 (TA instruments) at the cooling/heating rate of $1{ }^{\circ} \mathrm{C} / \mathrm{min}$, using TA Universal Analysis software for data analysis. The excipients added by buffer exchange prior to DSC analysis were as follows; (i) based upon that reported by Pfizer 2012, Benefix$8 \mathrm{mM}$ L-histidine, $23 \mathrm{mM}$ sucrose, $0.004 \%$ (v/v) polysorbate $80,208 \mathrm{mM}$ glycine $(40 \mathrm{mM} \mathrm{NaCl}$ added later, by means of the reconstitution solvent); (ii) based upon that reported by (Baxalta Canada Corporation 2015), Rixubis, $20 \mathrm{mM}$ L-histidine, $35 \mathrm{mM}$ sucrose, $60 \mathrm{mM} \mathrm{NaCl}, 0.005 \%$ (v/v) polysorbate 80 , $4 \mathrm{mM} \mathrm{CaCl}_{2}, 110 \mathrm{mM}$ mannitol.

\section{Comparison of lyophilization methods}

Samples were prepared at $250 \mu \mathrm{g}$ protein/ml and analyzed in triplicate for each condition. Two different lyophilization methods were compared, using the formulations of commercial products Benefix and Rixubis: (i) a method adapted from Ronzi et al. (2003), which was proposed for lyophilization of Factors VIII and IX, and (ii) a method adapted from Tang and Pikal (2004), which was proposed for biopharmaceuticals in 
Table 1 Lyophilization method adapted from Tang and Pikal (2004)

\begin{tabular}{|c|c|c|c|c|c|c|c|}
\hline \multirow[t]{2}{*}{ Step } & \multicolumn{3}{|l|}{ Freezing } & \multicolumn{4}{|l|}{ Primary drying } \\
\hline & Temperature $\left({ }^{\circ} \mathrm{C}\right)$ & Time (min) & Ramp/hold & Temperature $\left({ }^{\circ} \mathrm{C}\right)$ & Time (min) & Vacuum (mTorr) & Ramp/hold \\
\hline 1 & 25 & 15 & $\mathrm{H}$ & -40 & 30 & 100 & $\mathrm{H}$ \\
\hline 2 & 5 & 20 & $\mathrm{R}$ & -20 & 40 & 100 & $\mathrm{R}$ \\
\hline 3 & 5 & 30 & $\mathrm{H}$ & -20 & 1200 & 100 & $\mathrm{H}$ \\
\hline 4 & -5 & 10 & $\mathrm{R}$ & -20 & 1200 & 100 & $\mathrm{H}$ \\
\hline 5 & -5 & 30 & $\mathrm{H}$ & 25 & 450 & 100 & $\mathrm{R}$ \\
\hline 6 & -40 & 35 & $\mathrm{R}$ & \multicolumn{4}{|l|}{ Secondary drying } \\
\hline 7 & -40 & 120 & $\mathrm{H}$ & 25 & 360 & 100 & $\mathrm{H}$ \\
\hline 8 & -10 & 30 & $\mathrm{R}$ & - & - & - & - \\
\hline 9 & -10 & 120 & $\mathrm{H}$ & - & - & - & - \\
\hline 10 & -40 & 30 & $\mathrm{R}$ & - & - & - & - \\
\hline 11 & -40 & 120 & $\mathrm{H}$ & - & - & - & - \\
\hline
\end{tabular}

Table 2 Lyophilization method adapted from Ronzi et al. (2003)

\begin{tabular}{|c|c|c|c|c|c|c|c|}
\hline \multirow[t]{2}{*}{ Step } & \multicolumn{3}{|l|}{ Freezing } & \multicolumn{4}{|l|}{ Primary drying } \\
\hline & Temperature $\left({ }^{\circ} \mathrm{C}\right)$ & Time (min) & Ramp/hold & Temperature $\left({ }^{\circ} \mathrm{C}\right)$ & Time (min) & Vacuum (mTorr) & Ramp/hold \\
\hline 1 & 25 & 15 & $\mathrm{H}$ & -40 & 30 & 150 & $\mathrm{H}$ \\
\hline 2 & 5 & 20 & $\mathrm{R}$ & -30 & 60 & 150 & $\mathrm{R}$ \\
\hline 3 & 5 & 30 & $\mathrm{H}$ & -30 & 10 & 150 & $\mathrm{H}$ \\
\hline 4 & -5 & 10 & $\mathrm{R}$ & -15 & 240 & 150 & $\mathrm{R}$ \\
\hline 5 & -5 & 30 & $\mathrm{H}$ & -15 & 10 & 150 & $\mathrm{H}$ \\
\hline 6 & -40 & 35 & $\mathrm{R}$ & -5 & 240 & 150 & $\mathrm{R}$ \\
\hline 7 & -40 & 120 & $\mathrm{H}$ & -5 & 10 & 150 & $\mathrm{H}$ \\
\hline 8 & -10 & 30 & $\mathrm{R}$ & -5 & 30 & 120 & $\mathrm{H}$ \\
\hline 9 & -10 & 120 & $\mathrm{H}$ & Secondary drying & & & \\
\hline 10 & -40 & 30 & $\mathrm{R}$ & 25 & 600 & 120 & $\mathrm{R}$ \\
\hline 11 & -40 & 120 & $\mathrm{H}$ & - & - & - & - \\
\hline
\end{tabular}

general. The freeze drying programs are described in Tables 1 and 2.

Formulation design based on design of experiments (DoE)

A resolution IV, 2-level fractional factorial design with 8 factors (5 numeric and 3 categorical) and 32 centre points (4 replicates for each combination of categorical factors), with a total of 48 runs, was carried out to investigate concentrations and combinations of different excipient classes (cryoprotectant, buffer, salt, bulking agent and surfactant) in the rFIX formulation
(Supplementary Table 1). Samples were prepared at $250 \mu \mathrm{g}$ protein $/ \mathrm{ml}$. The responses investigated were cake appearance and rFIX activity after reconstitution with $1 \mathrm{ml}$ ultrapure water.

Freeze drying microscopy (FDM) to further assess the influence of $\mathrm{NaCl}$

To further investigate the effects of $\mathrm{NaCl}$ on the freezing and lyophilization behavior (nucleation temperature, collapse and eutectic melting), formulation \#6 of the DoE study (without $\mathrm{NaCl}$ ) and its version with $40 \mathrm{mM} \mathrm{NaCl}$ were evaluated by freeze drying 
microscopy (FDM), using a Lyostat 2 freeze-drying microscope (Biopharma Technology) coupled to an Olympus Plan C 10x/0.25 camera.

Assessment of rFIX protein stability after lyophilization in different formulations

Four different formulations were defined and compared to the formulation of commercially available Benefix based upon the initial studies reported here. The components of these four formulations A, B C and $\mathrm{D}$ can be found in Table 3. Samples were reconstituted with $0.234 \%(\mathrm{w} / \mathrm{v}) \mathrm{NaCl}$ in ultrapure water, which is the same as the solution supplied with Benefix. Samples were prepared to $300 \mu \mathrm{g}$ protein $/ \mathrm{ml}$, and each formulation was run in duplicate. Vials without excipients, containing only rFIX, were also lyophilized to confirm that the excipients were required to protect the protein against the stresses imposed by lyophilization process.

Factor IX samples were analyzed for residual moisture, cake appearance, the presence of aggregates (soluble and insoluble), and biological activity after reconstitution as described below. Stability upon lyophilization only was evaluated by reconstituting and analyzing vials immediately after lyophilization (time point $\mathrm{T}_{0}$ ), whereas stability upon storage at $2-8{ }^{\circ} \mathrm{C}$ and at room temperature was analyzed upon reconstitution after 90 days of storage (time point $\left.\mathrm{T}_{90}\right)$.
For the evaluation of accelerated degradation, lyophilized vials were stored at $40{ }^{\circ} \mathrm{C}$ for 45 days (time point $\mathrm{T}_{45}$ ) and for 90 days (time point $\mathrm{T}_{90}$ ), then reconstituted and analyzed. The conditions investigated are summarized in Table 4.

Analytical methods for factor IX analysis and characterization

\section{FIX activity assay}

Factor IX biological activity was determined using a commercial chromogenic kit (Biophen Factor IX kit, Hyphen Biomed, France), following the manufacturer's instructions.

\section{Karl Fischer titration}

Residual water analysis was determined on a C30 Colorimetric Karl Fischer Titrator (Mettler Toledo). An analytical balance (Mettler Toledo) was used to determine the mass of analyzed lyophilized samples.

\section{Soluble aggregate analysis by SEC-HPLC}

Samples were analyzed for monomer and soluble aggregate amounts using an HPLC. $100 \mu \mathrm{l}$ of sample was injected onto a TSK gel G3000 SWXL column $(5 \mu \mathrm{m}, 7.8 \times 300 \mathrm{~mm}$, Tosoh Bioscience, USA) was used to separate the monomers from the aggregated

Table 3 Components of the four different formulations investigated fora CHO-derived rFIX product

\begin{tabular}{lllll}
\hline Formulation & Cryoprotectant & Bulking agent & Buffering agent & Surfactant \\
\hline A & $40 \mathrm{mM}$ sucrose & $350 \mathrm{mM}$ glycine & $12.5 \mathrm{mM}$ L-histidine & $0.004 \%(\mathrm{v} / \mathrm{v})$ Polysorbate 80 \\
B & $40 \mathrm{mM}$ sucrose & $200 \mathrm{mM}$ mannitol & $12.5 \mathrm{mM}$ L-histidine & $0.004 \%(\mathrm{v} / \mathrm{v})$ Polysorbate 80 \\
C & $40 \mathrm{mM}$ trehalose & $350 \mathrm{mM}$ glycine & $12.5 \mathrm{mM}$ L-histidine & $0.004 \%(\mathrm{v} / \mathrm{v})$ Polysorbate 80 \\
D & $40 \mathrm{mM}$ trehalose & $200 \mathrm{mM}$ mannitol & $12.5 \mathrm{mM}$ L-histidine & $0.004 \%(\mathrm{v} / \mathrm{v})$ Polysorbate 80 \\
\hline
\end{tabular}

Table 4 Storage times and temperatures before reconstitution and analysis of Factor IX in formulations A-D and in Benefix formulation

Temperature of storage of lyophilized samples $\left({ }^{\circ} \mathrm{C}\right)$

Time of storage of lyophilized samples (days)

No storage (immediate reconstitution and analysis)

0

$4{ }^{\circ} \mathrm{C}$

90

Room temperature

90

$40{ }^{\circ} \mathrm{C}$ (accelerated degradation)

45 and 90 
species. A gel filtration standard (Bio-Rad, USA) was introduced at the start of the runs. The mobile phase was $0.1 \mathrm{M}$ anhydrous $\mathrm{Na}_{2} \mathrm{HPO}_{4} / 0.1 \mathrm{M} \mathrm{Na}_{2} \mathrm{SO}_{4}, \mathrm{pH}$ 6.8 , at $1 \mathrm{ml} / \mathrm{min}$ in isocratic mode.

\section{Dynamic light scattering (DLS) for analysis of insoluble aggregates}

A Zetasizer Nano (Malvern Instruments, USA) was used to determine the size of the particles based on DLS. $60 \mu \mathrm{l}$ sample was analyzed using ZEN2112 quartz cuvettes QS $300 \mathrm{~nm}$. The analysis was run in triplicate at $25^{\circ} \mathrm{C}$ with $60 \mathrm{~s}$ of equilibration time.

\section{Results and discussion}

A range of formulation excipients and combinations thereof, based upon literature and commercial Factor IX preparations, were investigated in order to develop a formulation for a recombinant FIX product with comparable stability using standard biochemical techniques. However, in order to address this question, it was initially necessary to develop an appropriate lyophilization process.

Definition of the lyophilization annealing temperature based on thermal analysis

Differential scanning calorimetry (DSC) analysis showed that both rFIX formulations investigate initially, containing the excipients of commercial rFIX products Benefix and Rixubis, ice nucleation temperature of approx. $-23{ }^{\circ} \mathrm{C}$, ice melting temperature of $0{ }^{\circ} \mathrm{C}$ and eutectic temperature $\left(\mathrm{T}_{\text {eu }}\right)$ of $-5{ }^{\circ} \mathrm{C}$ (Supplementary Fig. 1).

Ice formation during cooling of a protein solution concentrates all solutes which eventually changes the solution from a viscous liquid to brittle glass. The temperature of this reversible transition for the freezeconcentrated solution is the glass transition temperature $\left(\mathrm{T}_{\mathrm{g}}{ }^{\prime}\right)$ of maximally freeze concentrated solution. The collapse temperature $\left(\mathrm{T}_{\mathrm{col}}\right)$ is the temperature at which the interstitial water in the frozen matrix becomes significantly mobile. $\mathrm{T}_{\text {col }}$ is closely related to $\mathrm{T}_{\mathrm{g}}{ }^{\prime}$, as $\mathrm{T}_{\text {col }}$ has been considered to be equivalent to $\mathrm{T}_{\mathrm{g}}{ }^{\prime}$ of an amorphous system or to the eutectic melting temperature of a crystalline system (Wang 2000). Above $\left(\mathrm{T}_{\mathrm{col}}\right)$ the freeze-dried product loses macroscopic structure and collapses during freeze drying. (Tang and Pikal 2004).

For the formulations containing crystalline components, which crystallize completely during freezing, the eutectic melting temperature becomes more relevant for the freeze drying process to get an elegant cake structure as crystallized excipients undergo melting at $\mathrm{T}_{\mathrm{eu}}$ (Pansare and Patel 2016). In this case, is preferable that these excipients crystallize completely during freezing in order to prevent crystallization during storage. The annealing step is a hold step at a temperature above $\mathrm{T}_{\mathrm{g}}{ }^{\prime}$ that is frequently necessary to allow efficient crystallization of crystalline components, such as mannitol or glycine (Kasper 2011). The eutectic temperature can be used to estimate the annealing temperature of the freeze-drying process. However, to maintain a safe margin from $\mathrm{T}_{\mathrm{eu}}$, we defined an annealing temperature of $-10{ }^{\circ} \mathrm{C}$ for use in both lyophilization methods.

\section{Comparison of lyophilization methods}

Samples from the two different freeze-drying protocols investigated showed different macroscopic structures. The protocol adapted from Tang and Pikal (2004) had an elegant cake appearance for Factor IX formulated in the Benefix formulation, but not for Rixubis formulation. The protocol adapted from Ronzi et al. (2003) did not give a good cake appearance for either formulation, presenting a very fragile cake (Fig. 1). The method adapted from Ronzi was performed using more aggressive conditions with a shorter drying time performed at higher temperature and higher pressure. A more traditional approach, in this case yielded a better cake appearance, despite the whole process being five times longer. The rFIX activity after reconstitution of the material lyophilized according to Tang and Pikal (2004) was $42.2 \pm 7.0 \mathrm{IU} / \mathrm{ml}$ for the Benefix formulation and $35.1 \pm 4.6 \mathrm{IU} / \mathrm{ml}$ for the Rixubis formulation. On the other hand, the activity of rFIX lyophilized using the method adapted from Ronzi et al. (2003) was $34.3 \pm 7.8 \mathrm{IU} / \mathrm{ml}$ and $38.1 \pm 3.8$ for the Benefix and Rixubis formulations, respectively. The biological activity prior to lyophilization was $47.3 \pm 4.1 \mathrm{IU} / \mathrm{ml}$; therefore, for the Tang and Pikal method, this represents a recovery of approx. 90 and 74\% for Benefix and Rixubis formulations, respectively. For the Ronzi lyophilization method with the same starting material, 

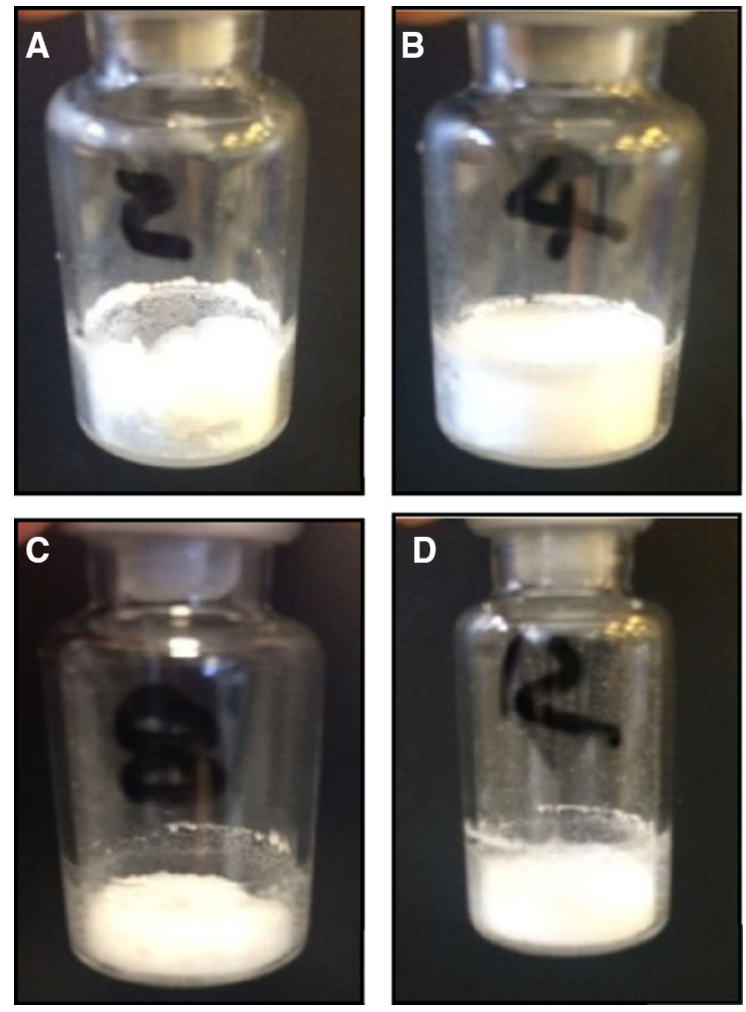

Fig. 1 Cake appearance of samples formulated with Benefix (top) and Rixubis (bottom) excipients and lyophilized according to the methods adapted from Ronzi et al. (2003) (a and c) and from Tang and Pikal (2004) (b and d)

approximately 73 and $80 \%$ of biological activity was recovered for the Benefix and Rixubis formulations, respectively. There was no significant difference in the activity between the two methods, however, even if the product is biologically active, a collapsed structure is not acceptable according to the quality standards of the industry (Ronzi et al. 2003). Therefore, based on the cake appearance further experiments were undertaken using the Tang and Pikal (2004) method and the proposed formulations were compared to the Benefix formulation.

The excipients used in the commercial formulations were assumed to be suitable for other $\mathrm{CHO}$ derived recombinant FIX products though perhaps could be further optimized for this specific FIX product using Design of Experiments. These excipients are also among the most commonly used for formulation of protein based biopharmaceutical products due their ability to protect protein during lyophilization. Disaccharides are used as cryoprotectants to prevent conformational changes and degradation during freezing in lyophilized formulations. Sucrose and trehalose are commonly used disaccharides (Povey et al. 2009), with trehalose sometimes preferable as a lyoprotectant for biomolecules due to its higher glass transition temperature.

Surfactants have been used to maintain the integrity of proteins against surface-induced degradations derived from agitation, filtration, filling, freeze-thawing and other stresses that may be encountered by the product. Polysorbate 80 (Tween 80 ) is one of the most common surfactants for protein stabilization during freezing, and concentrations from 0.005 to $0.01 \%$ (v/ v) have been used to protect several proteins from freezing denaturation (Wang 2000). Specifically, Bush et al. (1998) found that the addition of $0.005 \%(\mathrm{v} / \mathrm{v})$ polysorbate 80 to a recombinant FIX formulation was effective in reducing inactive high molecular weight aggregates. Buffering agents are important for maintaining the $\mathrm{pH}$ of the solution within an acceptable range. From a panel of buffering agents varying from 7 to 7.5 examined by Bush et al. (1998), including sodium phosphate, potassium phosphate and Tris, histidine was reported to be an excellent buffering agent for minimizing aggregation of lyophilised rFIX during storage at $30{ }^{\circ} \mathrm{C}$.

Bulking agents are included in the formulations for various uses, such as to enhance the pharmaceutical elegance of the cake and to increase the density of the product (when the drug concentration is below 3\% w/w) (Jameel and Pikal 2010). The bulking agents most frequently used are glycine and mannitol, they are non-toxic, have high solubility and have been successfully used in a variety of protein formulations (Wang 2000). Furthermore, mannitol and glycine both crystalize easily, they are easy to reconstitute, and possess high eutectic temperatures ranging from approximately -1 to $-3{ }^{\circ} \mathrm{C}$, an attribute very useful in carrying out the primary drying at a high product temperature without collapse and loss of elegance (Jameel and Pikal 2010). $\mathrm{NaCl}$ was included in this study based on Lambert et al. (2007), who proposed Benefix reformulation using $\mathrm{NaCl}$ to increase ionic strength and so to prevent agglutinated red blood cells (RBC) in the intravenous tubing (whilst still retaining iso-osmolality). After lyophilization and reconstitution of the different DoE samples, analysis of the rFIX activity showed no statistically significant differences within the ranges of the different factors investigated 
here. However, a low bulking agent/cryoprotectant mass ratio $(w / w)$ in combination with the presence of $\mathrm{NaCl}$ had a negative impact on cake appearance. This ratio has an impact on the $\mathrm{Tg}$ ' and may therefore influence the primary drying temperature. Some authors recommend that the bulking agent/cryoprotectant mass ratio should be at least 2 (see for example Johnson et al. 2002; Liao et al. 2005).

A poor cake appearance is characterized by shrinkage, cracks and fragility. For the majority of the formulations investigated here with a bulking agent to cryoprotectant mass ratio below $2: 1$, in combination with the lyophilization process used, the cake appearance was poor. However, in a number of the formulations investigated where $\mathrm{NaCl}$ was absence, the cake appearance was considered appropriate (e.g. formulations 4, 6 and 12) even when the bulking agent/cryoprotectant mass ratio was low $(<2)$. Some formulations with a bulking agent/cryoprotectant mass ratio $>2$ also showed an undesirable cake appearance when the $\mathrm{NaCl}$ was $80 \mathrm{mM}$ (e.g. formulations 3 and 5), thus when high concentrations of $\mathrm{NaCl}$ are present, even higher bulking agent/cryoprotectant mass ratios (e.g. $>10$ ) are needed to guarantee an adequate cake, such as in formulation 13 (Supplementary Table 2). Optimization of the lyophilization process could potentially solve this issue allowing the use of $\mathrm{NaCl}$ in the formulation and a lower bulking agent/cryoprotectant mass ratio. Several key process parameters could be optimized to ensure a good cake appearance using the excipients above, for instance, the freeze ramp rate, the final temperature of each step, chamber pressure and time. However, a simple solution could be to simply reconstitute with a $\mathrm{NaCl}$ solution.

\section{Evaluation of $\mathrm{NaCl}$ effects by freeze drying microscopy}

Freeze drying microscopy was performed on formulation 6 in the presence and absence of $\mathrm{NaCl}$ to compare the effect of the salt on critical temperatures of the freeze-drying process, especially on the collapse event. This analysis showed a significant difference between the collapse temperature $\left(\mathrm{T}_{\mathrm{col}}\right)$ of these 2 conditions as expected. As shown in Fig. 2, $\mathrm{T}_{\text {col }}$ was $-24.1{ }^{\circ} \mathrm{C}$ for the sample without $\mathrm{NaCl}$, and $-35.4{ }^{\circ} \mathrm{C}$ for the sample with $\mathrm{NaCl}$. Since salts exhibit low $\mathrm{T}_{\mathrm{g}}{ }^{\prime}$ values, even low $\mathrm{NaCl}$ concentrations $(<0.2 \% \mathrm{~m} / \mathrm{v}$ or $34 \mathrm{mM}$ ) can significantly depress the $\mathrm{T}_{\mathrm{g}}{ }^{\prime}$ values (Passot et al. 2010). When the product temperature exceeds the $\mathrm{T}_{\mathrm{g}}{ }^{\prime}$ value during the lyophilization process, the rigid glass softens to become a highly viscous rubbery material and collapses.

We next investigated removing factors with a negative effect on formulation, for example, the $\mathrm{NaCl}$ due its influence on $\mathrm{T}_{\mathrm{g}}{ }^{\prime}$ decrease and the potential longer term effect on stability. The bulking agent/ cryoprotectant mass ratio was established as being maintained at a minimum of 2 , and the histidine and polysorbate 80 concentrations in all new formulations were fixed based on literature (Bush et al. 1998; Wang
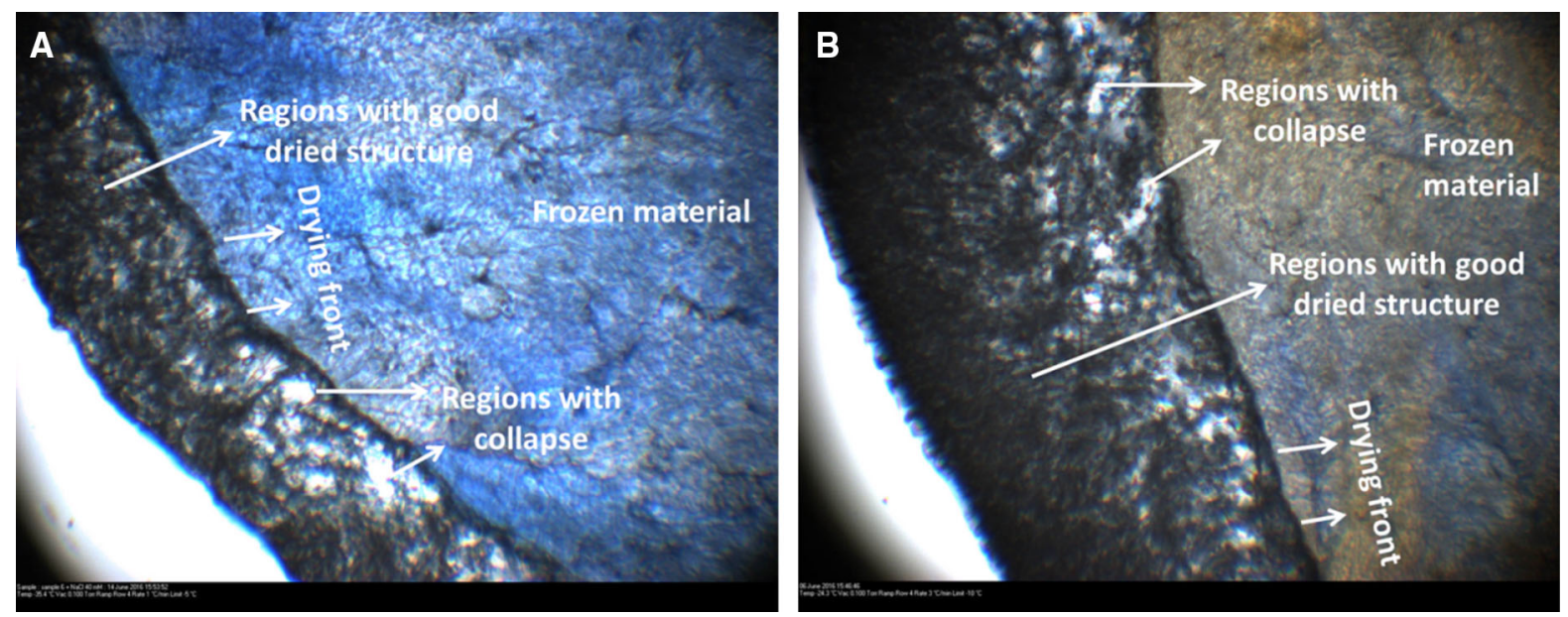

Fig. 2 Freeze-drying microscopy images of sample 6 from the DoE study, with (a) and without (b) NaCl. The temperature at which the collapse began to be observed was -35.4 and $-24.1{ }^{\circ} \mathrm{C}$, respectively. The annealing conditions used were $-10{ }^{\circ} \mathrm{C}$ for 10 min 

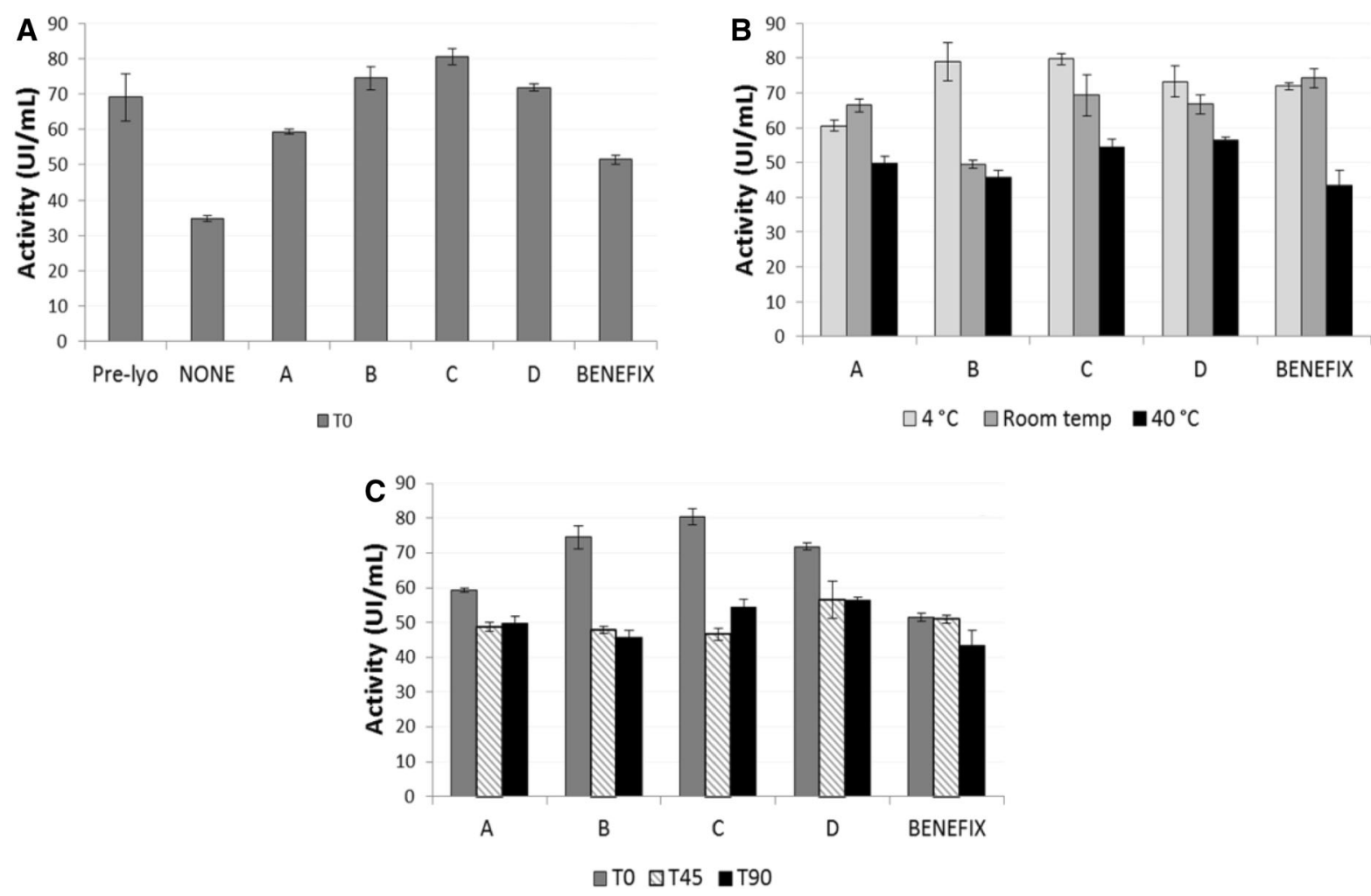

Fig. 3 FIX activity chart from formulations a-d and from rFIX formulated with Benefix excipients. a represents $\mathrm{T}_{0}, \mathbf{b} \mathrm{T}_{90}\left(4{ }^{\circ} \mathrm{C}\right.$, room temperature and $40{ }^{\circ} \mathrm{C}$ ) and $\mathbf{c} \mathrm{T}_{0}, \mathrm{~T}_{45}$ and $\mathrm{T}_{90}$ stored at $40{ }^{\circ} \mathrm{C}$. Error bars represent standard deviations $(\mathrm{n}=3)$

2000). This rationale resulted in four new formulations (named A-D), which were compared to the Benefix formulation. All five formulations showed an elegant cake appearance, whereas the condition without excipients looked to have collapsed as expected (Supplementary Fig. 2).

The average FIX activity prior to lyophilization was $69.1 \pm 6.6 \mathrm{IU} / \mathrm{ml}$. The rFIX activity measured in formulations A, B, C and D was more-or-less the same upon reconstitution immediately after lyophilization, compared with the starting value (Fig. 3a). The activity in the samples with no excipients decreased dramatically as expected compared with the values before lyophilization and all five formulations tested after lyophilization, highlighting the importance of a combination of excipients to protect the protein, maintaining stability and activity.

The longer-term stability study at different temperatures (Fig. 3b) showed little change in Factor IX activity in the different formulations stored at $4{ }^{\circ} \mathrm{C}$ for 3 months $\left(\mathrm{T}_{90}\right)$ when compared to the respective first time point $\left(\mathrm{T}_{0}\right.$, Fig. 3a). The same was observed for samples stored at room temperature, except for formulation $\mathrm{B}$, where storage at room temperature resulted in lower activity. In the samples stored at $40{ }^{\circ} \mathrm{C}$ (accelerated degradation study) there was a large decrease in observed FIX activity. At this higher temperature, results were equivalent for samples stored for 45 and 90 days (Fig. 3c).

When the residual water was analyzed in samples over time, only the Benefix formulation showed an increase in residual moisture as shown in Fig. 4, but not above the levels recommended in the literature, e.g. 3\%, after 3 months (Passot et al. 2010). The other formulations showed no significant change over 3 months. Further analysis for the presence of aggregates revealed that samples purified from batch mode CHO cultivation had FIX monomer proportions of 95\% and that the $\mathrm{T}_{0}$ samples all had monomer proportions of $92.2-93.5 \%$ (Fig. 5). This indicates that aggregate formation due to lyophilization was small and that most product aggregates found were 

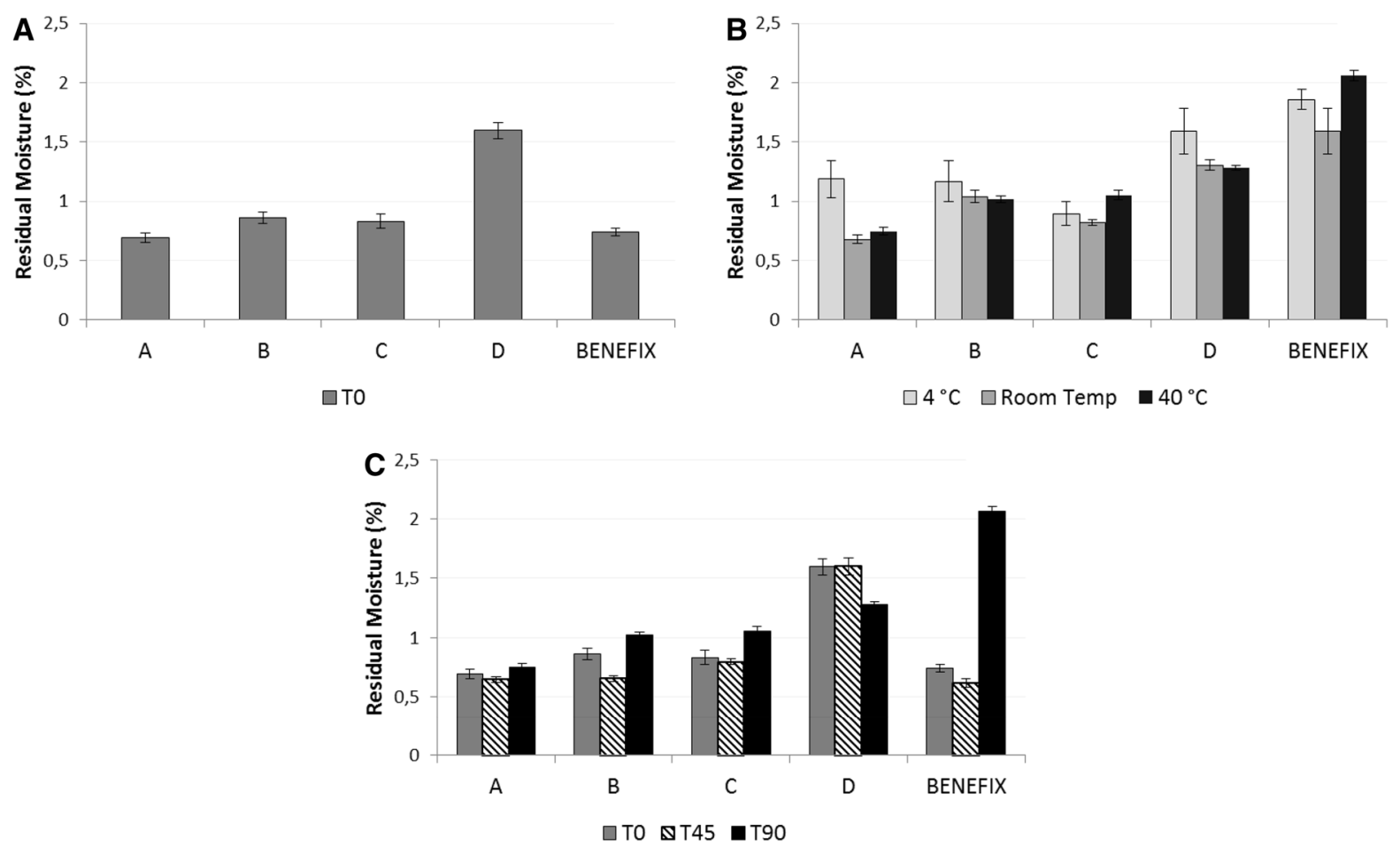

Fig. 4 Residual moisture measured by Karl Fisher titration on formulations a-d and from rFIX formulated with Benefix excipients. a represents $\mathrm{T}_{0}, \mathbf{b} \mathrm{T}_{90}$ (stored at $4{ }^{\circ} \mathrm{C}$, room temperature and $40{ }^{\circ} \mathrm{C}$ ) and $\mathbf{c} \mathrm{T}_{0}, \mathrm{~T}_{45}$ and $\mathrm{T}_{90}$ stored at $40{ }^{\circ} \mathrm{C}$

already present in the samples. The proportion of aggregates was substantially higher in samples with no excipients. All four formulations were equivalent to the Benefix formulation in terms of particle size distribution (Supplementary Fig. 3) and cake appearance (Supplementary Fig. 2). Dynamic light scattering indicated that the aggregates detected by SEC-HPLC had a heterogeneous size distribution.

\section{Conclusions}

Formulations B, C and D are suitable for formulating recombinant FIX as they give comparable data to that obtained with the formulation of commercially-available Benefix using the freeze-drying protocol adapted from Tang and Pikal (2004), when stored at $2-8{ }^{\circ} \mathrm{C}$ after lyophilization for at least 3 months in line with the approved shelf life temperature for commercial recombinant FIX according to the EMEA (2005). The use of the different excipients and concentrations reported here therefore represent an alternative to the commercial Benefix formulation for lyophilization of factor IX. Further, the use of mannitol could impact upon the formulation costs since this excipient is cheaper than glycine. Furthermore, whilst trehalose is more expensive compared to sucrose, trehalose has a higher $\mathrm{T}_{\mathrm{g}}{ }^{\prime}$ (consequently increasing the formulation $\mathrm{T}_{\mathrm{g}}{ }^{\prime}$ ) making possible the use of higher temperatures during the lyophilization. This would, in turn, enable significant time and cost savings through process optimization. Additionally, modification to the protein can occur due to glycation as a result of sucrose hydrolysis to yield reducing sugars (Smales et al. 2002), this would not occur with trehalose. Vials without excipients, containing solely rFIX protein, showed significant activity loss and higher levels of soluble aggregates compared with all five formulations reinforcing the importance of a combination of excipients to maintain the stability of the recombinant FIX product during the freeze-drying process. Formulations B, C and D contain the surfactant polysorbate80 , sucrose or trehalose as cryoprotectant, mannitol or glycine as bulking agent, L-histidine as buffering 

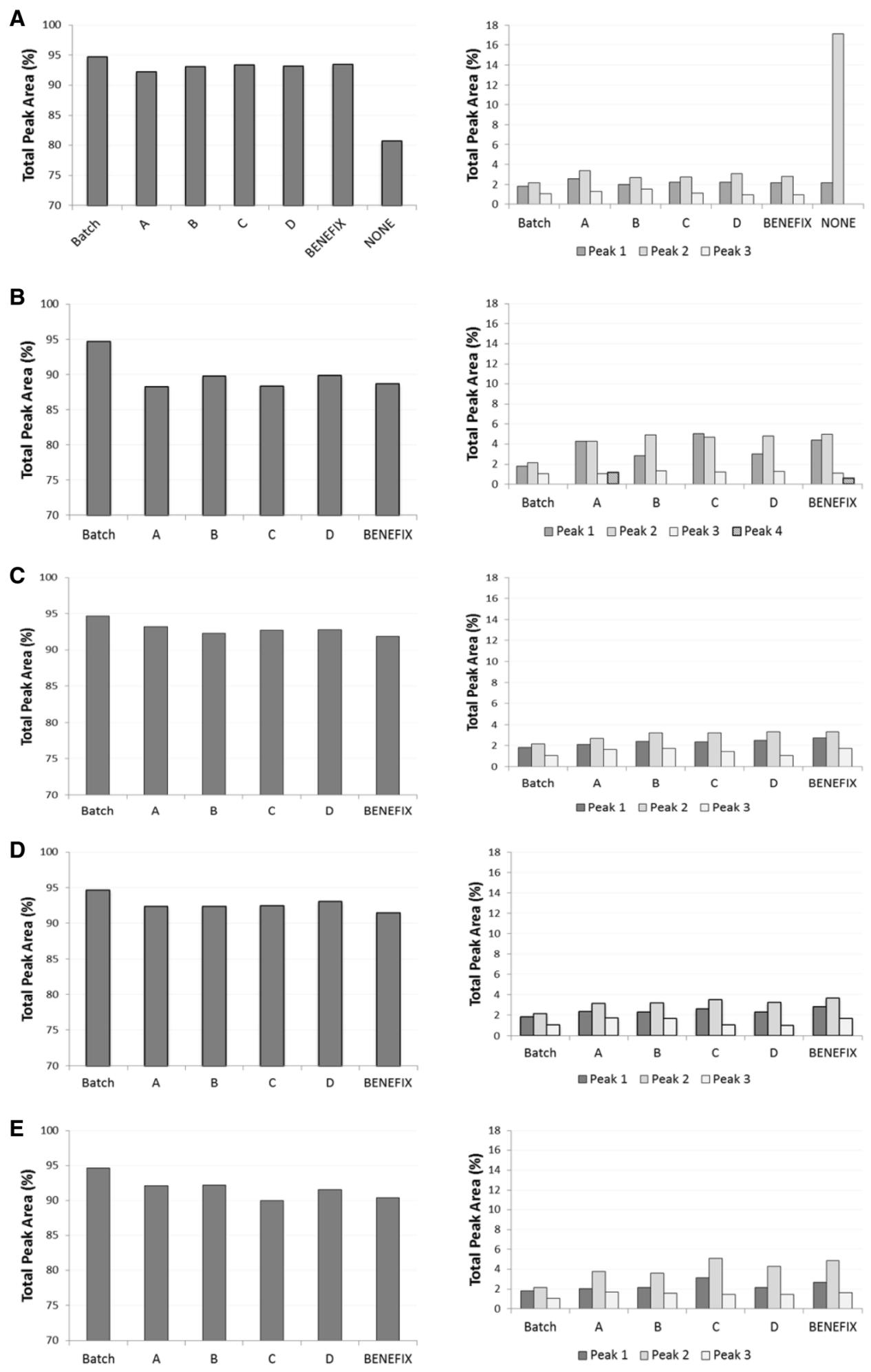

Fig. 5 Monomer (right) and soluble aggregate levels (left) measured by SEC-HPLC from formulations a-d and from rFIX formulated with Benefix excipients analyzed at three time points: $\mathrm{T}_{0}(\mathbf{a}), \mathrm{T}_{45}(\mathbf{b})$ and $\mathrm{T}_{90}$ at $4{ }^{\circ} \mathrm{C}(\mathbf{c})$, room temperature $(\mathbf{d})$ and $40{ }^{\circ} \mathrm{C}(\mathbf{e})$ 
agent, and $\mathrm{NaCl}$ added in the reconstitution liquid at a $0.234 \%(\mathrm{w} / \mathrm{v})$ concentration. We therefore propose these as alternative formulations for the protection of Factor IX during lyophilization and subsequent storage.

Acknowledgements The authors would like to thank CNPq, Capes, FAPERJ, BNDES, and Hemobras for the financial support of this research project, and the University of Kent for their support and laboratory facilities to enable these experiments. CMS thanks the Royal Society for an Industrial Fellowship (IF130004).

Supporting information Supplementary Table 1-Excipients and concentration ranges used in the Design of Experiments (DoE).

Supplementary Table 2-Two-level fractional factorial design of experiment (resolution IV) showing the 3 categorical factors and the 5 numeric factors (concentration ranges).

Supplementary Fig. 1-DSC thermal analysis of rFIX samples formulated with Benefix (A) and Rixubis (B) excipients.

Supplementary Fig. 2-Cake appearance after the lyophilisation of formulations A to D, rFIX formulated with Benefix excipients and the condition with no excipients (just rFIX).

Supplementary Fig. 3-Particle size profiles (by DLS) of formulations A to D, rFIX formulated with Benefix excipients and the condition with no excipients for all three time points analyzed.

\section{References}

Amaral RL, Bomfim AS, Abreu-Neto MS, Picanço-Castro V, Russo EMS, Covas DT, Swiech K (2016) Approaches for recombinant human factor IX production in serum-free suspension cultures. Biotechnol Lett 38:385-394

Baxalta Canada Corporation (2015) Product Monograph Rixubis Recombinant Coagulation Factor IX (rFIX), Nonacog gamma. http://www.baxalta.ca/downloads/Product_ Monographs/en/Rixubis.pdf. Accessed 4 November 2016

Bush L, Webb C, Bartlett L, Burnett B (1998) The formulation of recombinant factor IX: stability, robustness, and convenience. Semin Hematol 35:18-21

EMEA (2005) Scientific Discussion.http://www.ema.europa.eu/ docs/en_GB/document_library/EPAR_-_Scientific_ Discussion/human/000139/WC500020386.pdf. Accessed 12 March 2017

Gourbatsi E, Povey J, Uddin S, Smales CM (2016) Biotherapeutic protein formulation variables influence protein integrity and can promote post-translational modifications as shown using chicken egg white lysozyme as a model system. Biotechnol Lett 38:589-596

Jameel F, Pikal MJ (2010) Design of a formulation for freeze drying. In: Jameel F, Hershenson S (eds) Formulation and process development strategies for manufacturing biopharmaceuticals. Wiley, New Jersey, pp 459-492
Johnson RE, Kirchhoff CF, Gaud HT (2002) Mannitol-sucrose mixtures: versatile formulations for protein lyophilization. J Pharm Sci 91:914-922

Kasper JC (2011) The freezing step in lyophilization: physicochemical fundamentals, freezing methods and consequences on process performance and quality attributes of biopharmaceuticals. Eur J Pharm Biopharm 78:248-263

Lambert T, Recht M, Valentino LA, Powell JS, Udata C, Sullivan ST, Roth DA (2007) Reformulated BENEFIX: efficacy and safety in previously treated patients with moderately severe to severe haemophilia B. Haemophilia 13:233-243

Liao X, Krishnamurthy R, Suryanarayanan R (2005) Influence of the active pharmaceutical ingredient concentration on the physical state of mannitol-implications in freezedrying. Pharm Res 22:1978-1985

Lim I, Kim JS, Lee G, Choi M, Yoon Y (2010) The effects of medium supplement on high-level production of recombinant human factor IX in CHO cell. In: Noll T (ed) Cells and culture. Springer, Dordrecht, pp 613-618

Lim JY, Kim NA, Lim DG et al (2016) Process cycle development of freeze drying for therapeutic proteins with stability evaluation. J Pharm Invest 46:519-536

Pansare SK, Patel SM (2016) Practical considerations for determination of glass transition temperature of a maximally freeze concentrated solution. AAPS PharmSciTech 17:805-819

Passot S, Tréléa IC, Marin M, Fonseca F (2010) The relevance of thermal properties for improving formulation and cycle development: application to freeze-drying of proteins. In: Rey L, May JC (eds) Freeze drying/lyophilization of pharmaceutical and biological products, 3rd edn. Inf Healthc, New York, pp 136-166

Pfizer (2012) Product Monograph Benefix Coagulation Factor IX (recombinant). http://www.pfizer.ca/sites/g/files/ g10017036/f/201410/BENEFIX_PM_E_153056_ 27Dec2012.pdf. Accessed 4 November 2016

Povey JP, Perez-Moral N, Noel TR, Parker R, Howard MJ, Smales CM (2009) Investigating variables and mechanisms that influence protein integrity in low water content amorphous carbohydrate matrices. Biotechnol Prog 25:1217-1227

Ribeiro DA (2013) Processo de purificação de fator IX recombinante produzido em células da linhagem CHO. Ph.D. thesis, Federal University of Rio de Janeiro (Brazil)

Ribeiro DA, Passos DP, Ferraz HC, Castilho LR (2013) Anionexchange purification of recombinant factor IX from cell culture supernatant using different chromatography supports. J Chrom B 938:111-118

Ronzi E, Capolongo A, Rovero G, Bucci E, Mondini S, Falbo A (2003) Optimisation of a freeze-drying process of high purity factor VIII and factor IX concentrates. Chem Eng Proc 42:751-757

Smales CM, Pepper DS, James DC (2002) Protein modification during anti-viral heat-treatment bioprocessing of factor VIII concnetrates, factor IX concentrates, and model proteins in the presence of sucrose. Biotechnol Bioeng 77:37-48

Tang X, Pikal MJ (2004) Design of freeze-drying processes for pharmaceuticals: practical advice. Pharm Res 21:191-200 
Vatandoost J, Bos MH (2016) Efficient expression of functional human coagulation factor IX in stably-transfected Drosophila melanogaster S2 cells; comparison with the mammalian CHO system. Biotechnol Lett 38:16911698
Wang W (2000) Lyophilization and development of solid protein pharmaceuticals. Int J Pharm 203:1-60

Webb C, Bush L, Schaub RG (1997) Highly concentrated, lyophilized, and liquid factor IX formulations. Patent WO 1997026909:A1 